\title{
Natural course of Crohn's disease after ileocolic resection: endoscopically visualised ileal ulcers preceeding symptoms
}

\author{
G Olaison, K Smedh, R Sjödahl
}

\begin{abstract}
Forty two Crohn's disease patients were followed up after ileocolic resection with regard to symptoms and endoscopic appearance of the ileocolic anastomosis. Twenty eight patients resected because of colonic neoplasm served as controls. In all the Crohn's disease patients the ileal resection margin was disease free macroscopically at operation. In addition, intraoperative ileoscopy was performed in $\mathbf{1 3}$ and no sign of residual inflammation in the neoterminal ileum was seen. Endoscopy soon after surgery often showed preanastomotic ileal ulceration before symptoms appeared, whereas no anastomotic lesions were observed in the controls. Thus, 22 of $\mathbf{3 0}$ Crohn's disease patients examined had ulceration of the anastomotic area after three months, but only 10 had developed symptoms indicating relapse (73 $v$ 33\%). Corresponding figures in the 30 patients examined after one year were $93 v$ $37 \%$, and in 14 patients after three years they were 100 and $86 \%$ respectively. The inflammatory lesions in all cases were preanastomotic, in the neoterminal ileum, and showed time related progression from aphthae to larger ulcers and stricture. The study suggests that endoscopically observed inflammatory lesions that appear soon after ileocolic resection for Crohn's disease signify new inflammation and not residual, persistent disease or incomplete anastomotic healing. The data further suggest that despite clinical remission after apparently radical intestinal resection, the bowel is permanently inflamed in Crohn's disease.
\end{abstract}

Crohn's disease generally leads inevitably to severe intestinal inflammation and stricture. Resection of the diseased gut remains the standard option for the severely ill patient with defined segmental inflammation. Recurrence, however, is distressingly common, and it is now clearly established that surgery, even though apparently radical, offers no cure. The effect of surgery on the natural course of the disease is still controversial, and recurrence rates of $16-94 \%$ have been reported. ${ }^{1-11}$ This difference is not surprising, as the diagnostic criteria for recurrence are highly variable, ranging from clinical manifestations through radiological or histological evidence of disease to need for surgical intervention.

Recurrent lesions after ileocaecal resection for ileal disease or colectomy with ileorectal anastomosis for colitis tend to be localised to the region of the anastomosis. ${ }^{+1213}$ Morever, the overall postoperative recurrence rate was reported to be higher after colectomy and ileorectal anastomosis..$^{1+16}$ Colonoileoscopy provides unique opportunities for studying the early development of intestinal inflammation in this area.$^{17}$ In previous studies, ${ }^{18} 19$ a recurrence rate of $72-73 \%$ was found within a year of operation, and after three years it was $87 \% .^{19}$ Other authors ${ }^{2021}$ have described endoscopic lesions in the ileocolic anastomosis within two to six months in $70 \%$ of their patients, and postulated that these early lesions are not true recurrences, but merely recrudescing foci not removed at the time of resection.

This study examined the endoscopic appearance of the anastomotic area and its relation to symptoms after ileocolic resection or colectomy for Crohn's disease. Because we wished to clarify whether lesions seen at endoscopy were true recurrences or simply non-resected, residual disease, only patients without grossly visible residual intraoperative inflammation were admitted to the study. In order to elucidate whether early anastomotic lesions represent changes specific for Crohn's disease, patients who had undergone ileocolic resection and anastomosis because of colonic neoplasm served as controls.

\section{Patients and methods}

\section{CROHN'S DISEASE PATIENTS}

During the six year period $1984-90,55$ patients with Crohn's disease under surveillance at our hospital were treated with ileocolic resection. Forty two of these patients agreed to participate in the study. The male:female ratio was $26: 16$ and the age range was 11-75 (mean 39) years. The diagnosis was based on the Morson morphological criteria of resected tissue. ${ }^{22}$ Thirty four patients had primarily ileal disease. The operations comprised ileocaecal resection in 26 and anastomotic resection after primary ileocaecal resection in eight others. Eight patients had primarily Crohn's colitis, six of whom had no ileal involvement. Subtotal colectomy with ileocolic anastomosis was performed in three, and anastomotic resection because of ileal recurrence after colectomy was undertaken in another three. One patient required a left hemicolectomy with ileorectal anastomosis after right hemicolectomy and another a right sided hemicolectomy because of colitis and ileitis.

\section{CONTROL SUBJECTS}

Twenty eight patients who had undergone right sided hemicolectomy or ileocaecal resection 
(one) because of colonic carcinoma or large villous adenoma (two) served as controls. Their ages ranged from 30-79 years (mean 63 years).

\section{INTRAOPERATIVE PROCEDURE}

During operation the entire small and large bowel were carefully scrutinised for inflammatory lesions. To ascertain freedom from macroscopic inflammation at the resected margins, both the remaining intestine and the resected specimen were inspected. Intraoperative ileoscopy (Olympus CF-IBW or CF-10L colonoscope) of at least $30 \mathrm{~cm}$ of the residual neoterminal ileum was performed in the last 13 Crohn's disease patients, in all of whom the ileal mucosa was seen to be normal. The ileoscopy was performed in a retrograde fashion, and the ileum was distended with air as the bowel proximal to the endoscope was gently compressed. This technique allowed an excellent view of the distendended bowel. All resected tissue was examined histologically, with special emphasis on the presence of inflammation at the margins. Six patients showed microscopic inflammation at the ileal resection margin, and one of 13 patients who underwent perioperative ileoscopy showed marginal ileal inflammation.

In both groups the anastomosis was constructed as a conventional end to end anastomosis. A one or two layer closure with 3-0 or 4-0 polyglycolic acid (Dexon) was used.

\section{FOLLOW UP}

Crohn's disease patients were followed up with colonoileoscopy and evaluation of symptoms after 3 (range $1 \cdot 5-4 \cdot 5$ ) months, 12 (range 7-15) months, 24 (range 21-27) months, and 36 (range 35-39) months. Twelve patients were unwilling to undergo endoscopy after only three months, and were studied first after one year. Colonoscopy occasionally failed to show the anastomosis (after one year in two cases, after two years in two cases, and three years in two cases) and data from these examinations are not included in the report. During follow up two patients underwent further operation - one resection of the ileocolic anastomosis at 20 months and one left sided hemicolectomy at 52 months.

Control patients were investigated with colonoileoscopy after 6 (range 3-8) months in 12 cases, 12 (9-13 months) in 14 cases, and nine patients had an examination after $24(22-26)$ months.

TABLE I Endoscopic preanastomotic findings in the neoterminal ileum and cumulative simptomatic relapse at follow up after intestinal resection for Crohn's disease ${ }^{\star}$

\begin{tabular}{lllll}
\hline & \multicolumn{4}{l}{ Interval to follow up endoscopy } \\
\cline { 2 - 6 } & $\begin{array}{l}3 \text { mths } \\
(n=30)\end{array}$ & $\begin{array}{l}1 y r \\
(n=30)\end{array}$ & $\begin{array}{l}2 y r s \\
(n=17)\end{array}$ & $\begin{array}{l}3 y r s \\
(n=14)\end{array}$ \\
\hline Stage of inflammation: & $27 \%(8)$ & $7 \%(2)$ & $6 \%(1)$ & 0 \\
0 None visible & $13 \%(4)$ & $37 \%(11)$ & $17 \%(3)$ & $14 \%(2)$ \\
1 Aphthous ulcers & $33 \%(10)$ & $27 \%(8)$ & $41 \%(7)$ & 0 \\
2 Ulcers <4 mm & $7 \%(2)$ & $10 \%(3)$ & $12 \%(2)$ & $36 \%(5)$ \\
3 Ulcers 4-8 mm & $20 \%(6)$ & $17 \%(5)$ & $12 \%(2)$ & $43 \%(6)$ \\
4 Ulcers >8 mm & - & $3 \%(1)$ & $12 \%(2)$ & $7 \%(1)$ \\
5 Fibrotic stricture, diam 4-8 mm & - & - & - & - \\
6 Fibrotic stricture, diam <4 mm & $33 \%(10)$ & $37 \%(11)$ & $82 \%(14)$ & $86 \%(12)$ \\
Symptomatic relapse: $\dagger$ & \multicolumn{3}{l}{}
\end{tabular}

* Figures in brackets denote no of patients.

t Harvey-Bradshaw disease activity index $\geq 4$.
The endoscopic investigations were performed by two of the authors (GO and $\mathrm{KS}$ ), using an Olympus CF-10L or CF-IBW colonoscope. To confirm that the site of anastomosis had been adequately visualised, tissue for light microscopy was sampled immediately above and below the join. Intestinal inflammation was staged as in Table I.

In assessing the width of the anastomosis and the size of ulcers open biopsy forceps (width $8 \mathrm{~mm}$ :s) were used for comparison. Symptoms were assessed according to the Harvey-Bradshaw activity index. ${ }^{23}$ Scores of $\geq 4$ were classified as relapse.

\section{STATISTICS}

The two tailed Wilcoxon test corrected for ties, paired two tailed Wilcoxon test, and multiple regression were used for statistical analysis, with $\mathrm{p}<0.05$ considered significant. Survival rates without anastomotic inflammation and symptomatic relapse are shown in the Figure, values of missing observations have been inputed using estimated transition probabilities for guidance.

\section{Results}

Inflammatory lesions were visualised endoscopically in the region of the anastomosis in all 42 Crohn's disease patients but in no control subjects $(p<0.01)$. The endoscopic findings and the symptoms in Crohn's disease patients three months and one, two, and three years after operation are summarised in Table I. Inflammatory lesions appeared regularly above the anastomosis in the neoterminal ileum, and in patients without concomitant colitis the lesions were strictly confined to the neoterminal ileum. In no case did the inflammation overbridge the mucosal join. In patients with concomitant colitis, the inflammation was more pronounced above than below the anastomosis, where the inflammation was a part of the colitis in the remaining colon. After three months, $73 \%$ of the patients examined had ileal inflammation above the anastomosis, but only $33 \%$ had developed symptoms indicating relapse. After one year the corresponding figures were $93 \%$ and $37 \%$, and after two years they were $94 \%$ and $82 \%$. All of the 14 patients examined after three years showed ileal inflammation above the anastomosis and all but two had developed clinical relapse $(86 \%)$. Thirteen patients operated on during the same period, but not participating in the study, have been followed up with regard to symptoms. This group showed no difference $(p>0.05)$ in the rate of symptomatic relapse after three months $38 \%$ $(5 / 13)$, one year $62 \%(8 / 13)$, two years $62 \%$ $(8 / 13)$, and three years $69 \%(9 / 13)$.

Endoscopic findings at one year follow up after grouping according to colitis, microscopic inflammation at the ileal resection margin, primary $v$ further resection, short $v$ long duration of disease (more or less than seven years), and peforating $v$ non-perforating disease (according to Greenstein $e t a l)^{24}$ are shown in Table II. All of the six patients originally operated on for Crohn's colitis without ileal involvement developed ileal inflammation above the 


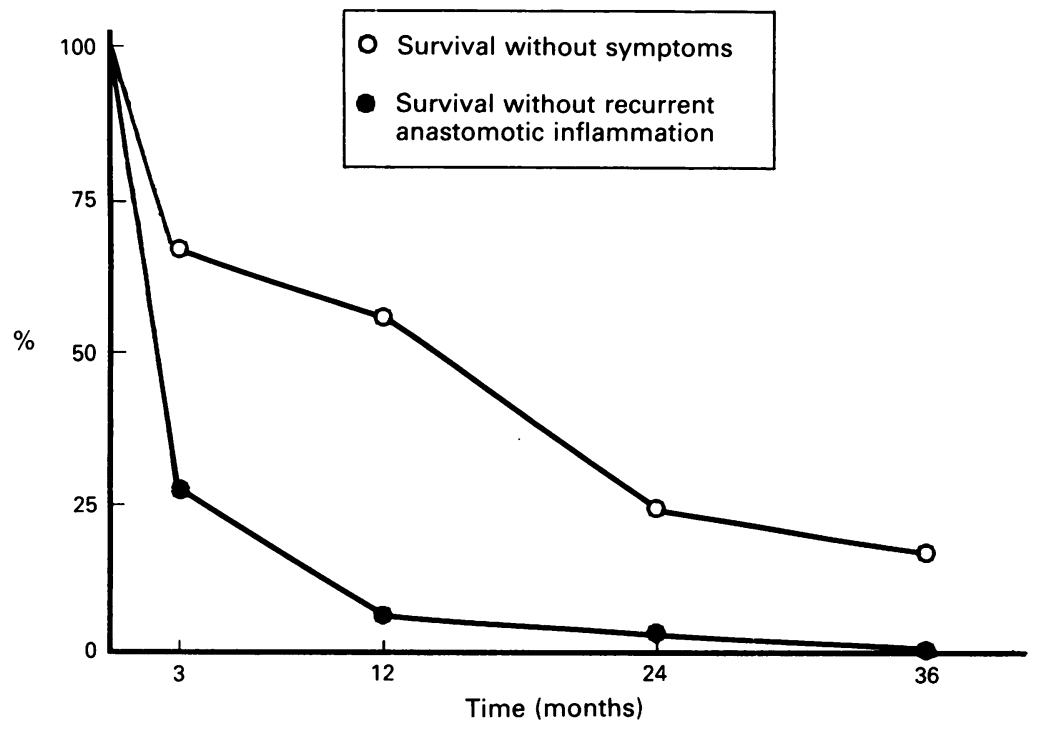

Survival without endoscopic anastomotic inflammation and symptomatic relapse in 42 patients with Crohn's disease followed up after ileocolic resection. The figure shows that anastomotic inflammation develops rapidly, is seen in all patients after three years, and preceeds symptomatic relapse.
TABLE II Mean endoscopic stage $e^{\star}$ of preanastomotic ileal inflammation one year after ileocolic resection in patients grouped according to variables

\begin{tabular}{ll}
\hline Variable & $\begin{array}{l}\text { Mean endoscopic } \\
\text { staget }\end{array}$ \\
\hline Colitis & $1 \cdot 9(7)$ \\
No colitis & $2 \cdot 1(23)$ \\
Microscopic inflammation at ileal margin & $2 \cdot 0(5)$ \\
No marginal inflammation & $2 \cdot 0(25)$ \\
Primary resection & $2 \cdot 2(18)$ \\
Re-resection & $1 \cdot 8(12)$ \\
Perforating disease & $2 \cdot 5(6)$ \\
Non-perforating disease & $1 \cdot 9(24)$ \\
Short disease duration $\ddagger$ & $2 \cdot 1(15)$ \\
Long disease duration & $2 \cdot 0(15)$ \\
\hline
\end{tabular}

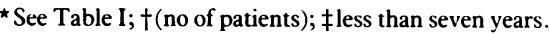

symptoms may not appear until the intestinal inflammation is fairly advanced. In Crohn's disease there may be an individual inflammatory burden, clinical evidence of which occurs only when a certain stage has been reached. Our rate of symptomatic relapse after surgery is higher than previously reported, ${ }^{1-16} 19$ but the figures are not biased by the group of patients unwilling to participate as their rate did not differ from the investigated group. This is, however, the first study in which patients followed up after surgery were evaluated prospectively by a Crohn's disease activity index, and studies that do not use a formal activity index may underscore the symptoms. Our figures are more similar to those in other prospective studies in patients with apparently quiescent disease at entry, where a Crohn's disease activity index of more than 150 was considered to indicate relapse, a figure equivalent to the $\geq 4$ Harvey-Bradshaw index in the present study. ${ }^{23}$ Relapse rates after one and two years were reported as 28 and $45 \%{ }^{25}$ and 51 and $66 \%{ }^{26}$ respectively in these studies, while we found rates of 37 and $82 \%$.

In our patients the incidence of anastomotic inflammation three months after operation was similar to previous reports, ${ }^{2021}$ but at subsequent endoscopies it was higher than in earlier studies (93-100 v 72-79\%).1819 27 In early inflammation the lesions are often discrete and recognisable only to the trained eye. Our figures may reflect substantial experience in performing endoscopy in Crohn's disease patients, resulting in the larger number of endoscopically detected lesions.

Our data do not support the view that recurrence of inflammation should be more common in Crohn's colitis than in ileal disease. In previous studies recurrence was commonly defined as a need for further resection 12710111314 and the high rates reported may be explained by exacerbation of inflammation in the remaining

TABLE III Individual course of preanastomotic ileal inflammation in seven patients endoscopically examined at all intervals after ileocolic resection

\begin{tabular}{lllll}
\hline \multirow{5}{*}{ Case no } & \multicolumn{4}{l}{ Endoscopic stage } \\
\cline { 2 - 5 } & At 3 mths & At l yr & At 2 yrs & At 3 yrs \\
\hline 1 & 1 & 2 & 5 & 5 \\
2 & 0 & 2 & 4 & 4 \\
3 & 0 & 1 & 1 & 3 \\
4 & 0 & 1 & 1 & 1 \\
5 & 1 & 1 & 2 & 4 \\
6 & 0 & 2 & 1 & 4 \\
7 & 0 & 1 & 2 & 3 \\
\hline
\end{tabular}

« See Table I. ulceloped symptomatic relapse A time related progression from aphthae to larger ulcers and stricture was observed. This observed progression suggests that the staging proposed by us (Table I) that describes the sequential development of recurrent anastomotic inflammation may be useful for evaluating the severity of the intestinal inflammation.

The findings suggest that clinically evaluable 
colon or rectum. Nor could we confirm previous data on higher recurrence rates after further resection than after primary resection. ${ }^{39-11}$ Likewise, disease duration or a history of perforating disease had no influence on the postoperative evolution of inflammatory lesions.

We were not able to visualise any anastomotic lesions in the patients resected because of colonic neoplasm, and in these patients we found complete healing of the anastomosis. They were followed up at a mean of six months, but some were seen after three months. All Crohn's disease patients retained their early ileal ulcers between three months and one year, and most showed progression. It is, thus, unlikely that early ulceration at the site of the anastomosis is a sign of incomplete healing or a reaction to sutures in the anastomosis, it probably represents lesions specific for Crohn's disease.

In the patients with Crohn's disease, recurrent anastomotic inflammation was always observed at the ileal side of the join, and in patients without concomitant colitis recurrent inflammation was confined to the neoterminal ileum. It is noteworthy that recurrence of inflammation above the anastomosis also developed in colitis patients without primary ileal involvement. Moreover, inflammation above the anastomosis was observed regardless of the operative procedure (ileocaecal resection, colectomy, or anastomotic resection). In addition, most patients followed showed progression to more severe ileal inflammation. These results, and the finding that the distal ileum is the prefered site for primary involvement in Crohn's disease, ${ }^{28}$ suggest that proximity to the colon may be harmful to the small intestine in this condition, and that colonic factors may contribute to small bowel inflammation. The low recurrence rate after colectomy with ileostomy, ${ }^{913}$ as well as previous findings that glucocorticoid treatment improves endoscopic colonic inflammation but not ileal inflammation above the anastomosis, as recently reported by us, ${ }^{29}$ underline the notion of inflammatory factors in the anastomotic area essentially affecting the distal ileum.

It has been suggested that inflammatory lesions found soon after intestinal resection represent residual inflammation not removed at surgery..$^{21}$ Our series, however, comprised only patients in whom ileal resection had been performed in tissue free from macroscopic disease. In the last 13 patients intraoperative ileoscopy further confirmed the absence of inflammation in the neoterminal ileum anastomosed to the colon. We had no problem scrutinising the distal ileum at either intraoperative endoscopy or when inspecting the resection margin. Our high frequency of postoperative lesions indicates a high sensitivity in detecting minor lesions and may to some extent validate the intraoperative investigation - minor lesions were not easily overlooked. Our findings agree with two previous studies. In one the patients had their distal ileum everted and inspected at the time of resection, and after six months 21 of 22 developed ileal ulcerations. ${ }^{19}$ In another, intraoperative ileoscopy was performed to confirm that $40 \mathrm{~cm}$ of the distal ileum was free from inflammatory lesions, and when followed
28 of 34 investigated patients had developed anastomotic lesions. ${ }^{30}$ It is arguable that early ulceration could develop from residual microscopic ileal lesions. Although microscopy showed inflammation at the ileal resection margin in a few cases in our series, this did not seem to be an important factor, as early endoscopic lesions could develop independently of these findings (Table II). Several earlier studies also indicated that residual microscopic inflammation at surgery did not influence the outcome. ${ }^{31} 32$ The inflammatory lesions found in our patients as early as three months postoperatively are more likely to represent true fresh inflammation.

The question of recrudescence or recurrence is, in our view, a matter of semantics. Although the intestinal inflammation most often seems to be regional, several studies indicate that Crohn's disease is a panenteric disease, with morphological and biochemical abnormalities in noninflamed mucosa also. ${ }^{33-36}$ A recent study also showed that a diffuse small intestinal inflammation was commonly encountered when endoscopy of the whole of the small bowel was performed intraoperatively. ${ }^{37}$ The anastomotic inflammatory lesions occurring soon after apparently radical ileocolic resection may be regarded as fresh inflammation or as recrudescence of a diseased mucosa prone to develop intestinal inflammation, or both.

The concept of 'recurrence after surgery' requires re-evaluation in Crohn's disease. On the one hand, our data favour the concept that early anasotomotic ileal inflammation is new (true recurrent) inflammation, but on the other such inflammation seems to be initiated almost immediately in most cases, and in most patients intestinal inflammation is present chronically. 'Clinical recurrence' may be used to denote overt disease, but 'recurrence' in the conventional sense of newly developed disease after an interval of health is inappropriate in the light of current data.

In summary, we found that ileal inflammation above the anastomosis is endoscopically detectable in many patients soon after resection for Crohn's disease, and that these lesions progress from aphthae to larger ulcers and stricture. Ulceration precedes symptoms, which do not occur until the intestinal inflammation has reached a certain stage. Anastomotic lesions occurring soon after intestinal resection represent new inflammation specific for Crohn's disease and not incomplete anastomotic healing or residual disease. Despite apparently radical resection with initial clinical remission, Crohn's disease is an ongoing process in which intestinal inflammation is permanently present.

This study was supported by grants from Östergötlands County Council, Swedish Society of Medicine, and Swedish Society for Medical Research.

1 Barber KW, Waugh JM, Beahrs OH, Sauer WG. Indications for and the results of the surgical treatment of regional enteritis. Ann Surg 1962; 156: 472-82.

2 Farmer RG, Hawk WA, Turnbull RB. Clinical patterns in Crohn's disease: a statistical study of 615 cases. Gastroenterology 1975; 68: 627-35.

3 Lennard-Jones JE, Stadler GE. Prognosis after resection of chronic regional ileitis. Gut 1967; 8: 332-6.

4 De Dombal FT, Burton I, Goligher JC. Recurrence of Crohn's disease after primary excisional surgery. Gut 1971; 12: 51927 .

\section{兴.} న N 
5 Lindhagen T, Ekelund G, Leandoer L, Hildell J, Lindström $\mathrm{C}$, Wenckert A. Crohn's disease in a defined population. Course and results of surgical treatment. 1 Small bowel disease. Acta Chir Scand 1983; 149: 407-13.

6 Hellberg G, Hulten L, Rosengren C, Ahren C. The recurrence rate after primary excisional surgery for Crohn's disease. Acta Chir Scand 1980; 146: 435-43.

7 Whelan G, Farmer RG, Fazio VW, Goormastic M. Recurrence after surgery in Crohn's disease. Relationship to location of disease (clinical pattern) and surgical indication. Gastroenterology 1985; 88: 1826-33.

8 Sachar DB, Wolfson DM, Greenstein AJ, Goldberg J, Styczynski R, Janowitz HD. Risk factors for postoperative recurrence of Crohn's disease. Gastroenterology 1983; 85: recurrence

9 Hellers G. Crohn's disease in Stockholm County 1955-1974. A study of epidemiology results of surgical treatment and study of epidemiology results of surgical treatment and
longterm prognosis. Acta Chir Scand 1979; 145: (suppl 490) longte $1-84$.

10 Mekhjian HS, Switz DM, Watts HD, Deren JJ, Katon RM, Beman FM. National Cooperative Crohn's disease study: factors determining recurrence of Crohn's disease after surgery. Gastroenterology 1979; 77: 907-13.

11 Greenstein AJ, Sachar DB, Pasternack BS, Janowitz HD. Reoperation and recurrence in Crohn's colitis and ileicolitis. Crude and cumulative rates. $N$ Engl f Med 1975; 293: 68590.

12 Chardavoyne R, Flint GW, Pollack S, Wise L. Factors affecting recurrence following resection for Crohn's disease. Dis Colon Rectum 1986; 29: 495-502.

13 Kirsner JB. The local and systemic complications of inflammatory bowel disease. $\mathscr{F} A M A 1979 ; 242$ : 1177-83.

14 Fasth S, Hellberg R, Hulten L, Åhren C. Site of recurrence, extent of ileal disease and magnitude of resection in primary and recurrent Crohn's disease. Acta Chir Scand 1981; 147: $569-76$.

15 Himal HS, Belliveau P. Prognosis after surgical treatment for granulomatous enteritis and colitis. Am f Surg Gastroenterol $1981 ; 142: 347-9$.

16 Frikker $M J$, Segall $M M$. The resectional reoperation rate for Crohn's disease in a general community hospital. Dis Colon Rectum 1983; 26: 305-9.

17 Clavadetscher $P$. Deyhle P. Diagnosis of Crohn's recurrence after surgery. Endoscopy 1975; 7: 27-9.

18 Rutgeerts P, Geboes K, Vantrappen G, Kerremans R Coenegrachts JL, Coremans G. Natural history of recurren Coenegrachts JL, Coremans $G$. Natural history of recurrent surgery. Gut 1984; 25: 665-72.

19 Rutgeerts P, Geboes K, Vantrappen G, Beyls J, Kerremans R, Hiele M. Predictability of the postoperative course of Crohn's disease. Gastroenterology 1990; 99: 956-62.

20 Tytgat GNJ, Nio CY, Mulder CJJ. Le role de la coloscopie dans l'evaluation post-operatoire de la maladie de Crohn. Acta Endosc 1987; 17: 121-7.

21 Tytgat GNJ, Mulder CJJ, Brummelkamp WH. Endoscopic lesions in Crohn's disease early after ileocecal resection. Endoscopy 1988; 20: 260-2.
22 Morson BC. Histopathology of Crohn's disease. Proc $R$ Soc Med 1968; 61: 79-81.

23 Harvey RF, Bradshaw JM. A simple index of Crohn's disease activity. Lancet; 514

24 Greenstein AJ, Lachman P, Sachar DB, Springhorn J, Heimann T, Janowitz HD, et al. Perforating and nonperforating indications for repeated operations in Crohn's disease: Evidence for clinical forms. Gut 1988; 29 588-592.

25 Summers RW, Switz DM, Sessions JTJr, Becktel JM, Best WR, Kern FJr, et al. National Cooperative Crohn's Disease Study: results of drug treament. Gastroenterology 1979; 77 . $847-69$.

26 Malchow H, Ewe K, Brandes JW, Goebell H, Ehms H, Sommer H, et al. European Cooperative Crohn's Disease Study (ECCDS): results of drug treatment. Gastroenterology 1984; 86: 249-66.

27 Gabbert HE, Ewe K, Singe CC, Junginger T, Gerharz CD Köther K. Frührezidiv des Morbus Crohn nach "kurativer" leocaekalresektion. Dtsch Med Wochenschr 1990; 115: 44751 .

28 Mekhiian HS, Switz DM, Melnyk CS, Rankin GB, Brooks RK. Clinical features and natural history of Crohn's disease. Gastroenterology 1979; 77: 898-906.

29 Olaison G, Siödahl R, Tagesson C. Glucocorticoid treatment in ileal Crohn's disease: relief of symptoms but not of endoscopically viewed inflammation. Gut 1990;31: 325-8.

30 Lescut D, Vanco D, Colombel JF, Bonnière $P$, Quandalle $P$, Lecomte-Houcke $M$, et al. Influence des lesions endoscopiques d'amont sur les recidives endoscopiques anastomotiques (rea) au cours de la maladie de Crohn (MC) Gastroenterol Clin Biol 1990; 14: A20.

31 Pennington L, Hamilton S, Bayless TM, Cameron JL. Surgical management of Crohn's disease - Influence of disease at margin of resection. Ann Surg 1980; 192; 311-8.

32 Heuman R, Boeryd B, Bolin T, Siödahl R. The influence of disease at the margin of resection on the outcome of Crohn's disease. Br F Surg 1983; 70: 519-21

33 Cooper BT, Lucas ML, Lei FH, Blair JA, Cooke WT. Abnormal jejunal surface $\mathrm{pH}$ in Crohn's disease-new evidence that Crohn's disease is a diffuse lesion of the gastrointestinal tract. Gut 1977; 18: A423.

34 Dunne WT, Cooke WT, Allan RN. Enzymatic and morphometric evidence for Crohn's disease as a diffuse lesion of the metric evidence for Crohn's disease as a diffus

35 Olaison G, Sjödahl R, Tagesson C. Decreased gastrointestinal absorbtion of peroral polyethyleneglycol (PEG 1000) in absorbtion of peroral polyethyleneglycol (PEG 1000) in Crohn's disease-A sign

36 Rickert RR, Carter HW. The early ulcerative lesions of Crohn's disease: correlative light-and scanning electronmicroscopic studies. $\mathcal{F}$ Clin Gastroenterol 1980; 2: 11-9.

37 Lescut D, Colombel JF, Cortot A, Vanco D, Bonniere P, Quandalle $\mathrm{P}$, et al. Peroperative small bowel endoscopy in Crohn's disease. Eur f Gastroenterol Hepatol 1990; 2 (suppl 1): 559 